\title{
Transition Services in Eight Rural Counties of Western New York:
}

\author{
Views of Directors of Special Education
}

\author{
Bruce A. Shields \\ Mindy S. Scirri \\ Michael R. Berta \\ Daemen College \\ Kara M. Klump \\ Cantalician Center
}

\begin{abstract}
Although the P-12 setting has certain protections (Gargiulo, 2011), when students with special needs leave the school environment through graduation or aging out, transition services become paramount (Tillmann \& Ford, 2001). Transition caught the eye of the federal government as early as the 1980s (Zhang, Ivester, \& Katsiyannis, 2005). The Office of Special Education and Rehabilitative Services (OSERS) was created to administer programs educating children and youth with disabilities and provide funding to support transition programs, technical assistance projects and research projects related to youth with disabilities (U.S. Department of Education, 2012). Contemporary transition services have evolved from simply looking at independent and work environments to including post-secondary education, changing employment conditions, adult social services, community involvement, and vocational education (Wehman, 2013). Today, the attention to transition, especially for students with disabilities, has become even more crucial as educational reform initiatives increasingly focus on standards for college and career readiness.

Rural school districts face different challenges than urban and suburban districts. In fact, several Rural Systemic Initiatives (RSIs) have been established around the country to isolate and address rural school district issues (Harmon \& Smith, 2012). In order to improve the effectiveness of transition services in rural schools, feedback from stakeholders in the process is vital. Directors of special education, specifically, must work to facilitate a quality and seamless process for transition despite challenges, and those working in rural settings may face additional obstacles. This study examines the perspectives of these front-line providers in order to begin to understand the difficulties that rural school
\end{abstract}

districts, in particular, must overcome. The challenges and suggestions expressed by directors of special education impact the trajectory of improvements that need to be made in rural education transition services. These improvements will not only streamline processes for rural educators and staff involved in transition, but will ultimately benefit the families they serve.

\section{Method}

The current investigation uses a cross-sectional survey design to examine opinions of directors of special education regarding high school transition practices in their own rural school districts. Questionnaires were utilized to address transition topics that special education directors encounter daily: involvement of special education teachers, involvement of parents/guardians, involvement of the community, and involvement of BOCES. (In New York, the Board of Cooperative Educational Services [BOCES] provides shared services to participating school districts in designated regions.) These topics were chosen based on frequent encounters with directors of special education, teachers, and administrators within the eight counties of Western New York targeted in this convenience sample: Alleghany, Chautauqua, Cattaraugus, Erie, Genesee, Niagara, Orleans and Wyoming. Directors of special education in those districts were sent letters explaining that a survey URL link would be e-mailed to them to garner opinions about transition services in their own districts. Each response on the survey was based on a Likert scale ranging from "very satisfactory" to "very unsatisfactory," and there was an opportunity for respondents to provide written commentary as well. Of the 75 directors who were 
contacted, 30 returned useable surveys, which

resulted in a $40 \%$ response rate.

Table 1.

Response ratings of rural directors of special education on their transition services

\begin{tabular}{llllllll}
\hline$V S$ & $S$ & $S S$ & $N$ & $S U$ & $U$ & $V S$ & $N O$ \\
\hline
\end{tabular}

How would you rate your school's or district's transition services offered to your students?
$9(30)$
$13(43.4)$
7 (23.3)
$0(0.0)$
1 (3.3) $\quad 0(0.0)$
$0(0.0)$
$0(0.0)$

How would you rate the involvement of your special education teachers in transition services for your students with special needs?
11(36.7)
12 (40)
7 (23.3)
$0(0.0)$
$0(0.0)$
$0(0.0)$
$0(0.0)$
$0(0.0)$

How would you rate the involvement of parents/guardians in the transition services offered to your students with special needs?
$3(10)$
$10(33.3)$
12 (40)
$1(3.3)$
2 (6.7)
2 (6.7)
$0(0.0)$
$0(0.0)$

How would you rate the involvement of your community in the transition services offered to your students with special needs?
5 (16.7) 3 (10)
11 (36.7) 4 (13.3)
2 (6.7)
5 (16.7)
$0(0.0)$
$0(0.0)$

How would you rate the involvement of BOCES in the transition services offered to your students with special needs?

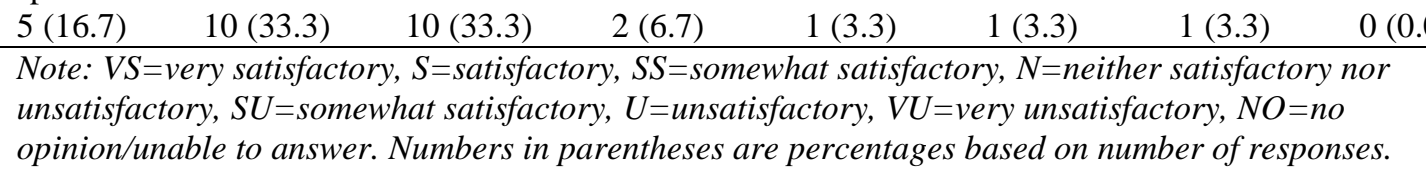

\section{Results}

Directors of special education who participated in this study indicated that they were satisfied with the transition services in their own districts; $96.7 \%$ ( 29 out of the 30 responses) of the directors rated their transition services as very satisfactory $(30 \%)$, satisfactory (43.4\%), or somewhat satisfactory $(23.3 \%)$. Such a high degree of satisfaction may be reflective of their quality transition services; however, the possibility of self-report bias cannot be dismissed. Examined more critically however, the results do indicate that there is room for improvement. Directors' comments indicate that their districts should have "support to offer multioccupational courses" and more "viable options for students needing to transition into supported employment and independent living situations."

The highest ratings related to directors' opinions about their own special education teachers' involvement with the transition services. A full 100\% are rated at somewhat satisfactory or higher. While these responses are subject to the same possible selfreport biases, the fact that $76.7 \%$ are satisfied or very satisfied may indicate that any gaps in quality are more likely to be due to factors other than the involvement of special education teachers. According to the Individuals with Disabilities Education Improvement Act (2004), transition planning must be addressed when students with disabilities turn 14 or 15 , and more in-depth plans must be included in the
Individual Education Planning (IEP) process at the age of 16. The bulk of the planning and implementation of transition falls to special educators as mandated by law. Directors offer no suggestions for how to increase involvement of their special education teachers in transition services.

Conversely, the degree of parental involvement in transition planning is not mandated by law. While statistically the opinions of the directors are favorable regarding parents'/guardians' involvement, there are also some ratings suggesting the need for improvement. Although $83.3 \%$ of the responses demonstrate that directors of special education are at least somewhat satisfied with the involvement of parents/guardians, there are more directors responding satisfactory $(33.3 \%)$ and somewhat satisfactory $(40 \%)$ than those responding very satisfactory $(10 \%)$. Directors' suggestions include the need for parents/guardians to take more ownership of their children's readiness to enter the workforce (i.e., being on time for school, following teacher directives, and supporting district efforts to foster independence), additional parent education and information about resources available within the county and outlying areas, and more proactive involvement in post-school planning especially where jobs are scarce or college may be an unrealistic option.

The results related to community involvement are the lowest among all of the questions. While $63.4 \%$ of the opinions are deemed in the satisfactory 
range, a full $36.6 \%$ are in the neutral to unsatisfactory range. Except for the $16.7 \%$ of directors who report being very satisfied with community involvement, there seems to be disengagement between the work performed within the schools in planning for transition and the ultimate implementation of the transition plans within the community. In their comments regarding community involvement, directors cite the challenge of building relationships with community organizations. Directors suggest more opportunities for unpaid internships, increased "community awareness and training to be able to support students with disabilities in local establishments," and more options for students to become gainfully employed especially in rural areas where "there are few jobs" and "transportation is a concern." One director, in a rural area with "very limited resources" suggests that "surrounding communities pool their resources" and/or "larger communities that have more resources reach out and open up these services to us." Directors want a layout of available options that may benefit each student, and they hope for "more community outreach at the state level to assist with transition." Another theme apparent in the directors' comments is that of a further need to help those students with less severe disabilities. One director asked for more community involvement particularly for "the students with more ability to learn more about the transition services." Another director complained that "employment preparation and support services are only available to the most disabled students," and another director noted that "there are no services for the "typical' LD student seeking options after high school." Thus, while community involvement may be lacking for those students with the most severe disabilities, there may be even fewer resources and supports for those with less severe disabilities - particularly in rural districts with already limited resources.

While not quite as undesirable as the community involvement ratings, the link between transition services and local BOCES organizations is also lacking for some districts. BOCES was originally created as a temporary "intermediate" school district to assist rural school districts to share resources that would otherwise be too expensive or too rare to provide in each district. As suggested in the comments, one way to improve this connection would be the completion of career development and occupations studies [CDOS] via BOCES career and technical education programs. Directors claiming disengagement with BOCES note the lack of occupational courses with work experience, unsatisfactory IEP follow-through, and limited communication as contributing factors. For one district, "BOCES is not a player in the transition field at this time," and for at least one district, "exit summaries are not always shared." There are, however, just as many results of very satisfactory interaction with BOCES (16.7\%) as there are for neutral to unsatisfactory interaction with BOCES $(16.7 \%)$, so variation in such relationships is evident among school districts.

\section{Discussion}

Directors of special education in the current sample were mostly satisfied with their own district practices and the efforts of their staff when providing transition services. However, in some rural school districts in Western New York, there appears to be a lack of synergy between school district staff, and parents/guardians, the community, and BOCES. If this aspect of coordination and communication can be overcome, the transition process will be more successful. Further, more attention may be necessary regarding the particular transition needs of students with less severe disabilities in these rural districts where resources are already limited. While the findings of this survey and the comments should be viewed with caution, as they represent a small survey sample of rural special education directors in Western New York, there exist strong opinions about transition services. Additional research is needed to determine if the transition needs of these districts are not so unique when compared to other rural counties. Further, additional research is necessary to examine opinions of other stakeholders in the transition process (i.e., students, parents/guardians, community organizations, and BOCES). The quantitative ratings and qualitative suggestions/comments provided by research studies like these may help guide reform of transition services. In rural school districts especially, where resources and opportunities may be more limited, the most effective and efficient use of transition services is crucial for the post-secondary success of the students with disabilities receiving those services. 


\title{
References
}

Gargiulo, R. M. (2011). Special education in contemporary society: An introduction to exceptionality ( $4^{\text {th }}$ ed). Los Angeles, CA: Sage.

Harmon, H. L., \& Smith, K. C. (2012). Legacy of the rural systemic initiatives: Innovation, leadership, teacher development, and lessons learned. Charleston, WV: Edvantia, Inc.

Individuals with Disabilities Education Improvement Act of 2004, 20 U.S.C. 1400 et seq. (2004).

Tillmann, J. D., \& Ford, L. (2001). Analysis of transition services of individualized education programs for high school students with special needs. Retrieved from ERIC database. (ED 456608)
U.S. Department of Education. (2012). OSERS transition data fact sheet. Retrieved from www2.ed.gov/about/offices/list/osers/products/t ransition/transition-datasheet-2011.doc

Wehman, P. (2013). Life beyond the classroom: Transition strategies for young people with disabilities ( $5^{\text {th }}$ ed.). Baltimore, MD: Brookes.

Zhang, D., Ivester, J., \& Katsiyannis, A. (2005). Teachers' views of transition services: Results from a statewide survey in South Carolina. Education and Training in Developmental Disabilities, 40(4), 360-367.

\begin{abstract}
About the authors:
Dr. Bruce Shields is an Associate Professor at Daemen College where he teaches principally in the area of special education. He has held various teaching, professional and administrative positions, working for organizations that provide service to people with disabilities and their families. In addition to his Ph.D. from the University at Buffalo, Dr. Shields also has two master's degrees: Master of Arts in Special Education (University of Missouri at Columbia) and a Master's of Education (University at Buffalo). His Bachelor's degree--in special and elementary education-was earned at Slippery Rock (PA) University.
\end{abstract}

Dr. Mindy Scirri is an Assistant Professor in the Education Department at Daemen College. A specialist in learning (dis)abilities, Dr. Scirri holds a Ph.D. in Special Education and a Master of Science degree in Learning Disabilities from Syracuse University. Additionally, she holds a Master of Arts degree in English/Creative Writing from Binghamton University and Bachelor of Art degrees from the University of Rochester in both Biology and Psychology. Dr. Scirri operates a private practice, Learnabilities, where she works with students and their families to help them negotiate students' K-12 education and/or college or vocational pursuits.

Dr. Michael Berta holds a BA in Psychology, a MA in Education, and an Ed.D. in Educational Leadership. Currently, he is the Director of Educational Development at Daemen College in the Center for Excellence in Teaching in Learning. His research areas include distance education, instructional technology, faculty development, and formative evaluation of teaching and learning.

Ms. Kara Klump earned a master's degree in special education and a bachelor's degree in childhood and student with disabilities from Daemen College. While there, she participated and held various board positions within special education and other student organizations. Currently, Kara is a teacher of students with special needs between the grades of three and five at the Cantalician Center for Learning Inc., in Depew, NY. 